\title{
Lessons Learned from Providing Hundreds of Hours of Diversity Training
}

\author{
Luther Tychonievich \\ University of Virginia \\ Charlottesville, Virginia \\ tychonievich@virginia.edu
}

\author{
James P. Cohoon \\ University of Virginia \\ Charlottesville, Virginia \\ cohoon@virginia.edu
}

\begin{abstract}
The past thirty years have seen many advances in our understanding of issues that impede diversity, as well as interventions that can remove or mitigate those impediments. The advances are generally presented in psychology journals and are under-consumed by computing educators, leading to the need for diversity training tailored to said educators. We have hundreds of hours of experience providing diversity training to computing educators, and have learned many lessons about how training should and should not be delivered to engage participants in understanding diversity-impeding forces and implementing interventions to improve the attraction and retention of diverse students.

This paper is a collection of those lessons learned. We focus on concrete approaches to presenting material rather than on training organization or content, including a dozen specific practices that have proven particularly effective or ineffective in reaching diverse audiences. Examples include how how to avoid offending participants, how to help experts not lose their audience, how to pace and organize material for maximum impact, how we tie many topics into a single cognitive framework, and how we've learned to handle participant-raised objections. We also include commentary as to why we believe they did or did not work. We also describe possible future research to validate and expand on our observations and a few open questions for diversity training.
\end{abstract}

\section{CCS CONCEPTS}

- Social and professional topics $\rightarrow$ User characteristics; Computing education programs; • Applied computing $\rightarrow$ Education.

\section{KEYWORDS}

diversity, professional development, teacher training

\section{ACM Reference Format:}

Luther Tychonievich and James P. Cohoon. 2020. Lessons Learned from Providing Hundreds of Hours of Diversity Training. In The 51st ACM Technical Symposium on Computer Science Education (SIGCSE '20), March 11-14, 2020, Portland, OR, USA. ACM, New York, NY, USA, 7 pages. https: //doi.org/10.1145/3328778.3366930

Permission to make digital or hard copies of part or all of this work for personal or classroom use is granted without fee provided that copies are not made or distributed for profit or commercial advantage and that copies bear this notice and the full citation on the first page. Copyrights for third-party components of this work must be honored.

For all other uses, contact the owner/author(s).

SIGCSE '20, March 11-14, 2020, Portland, OR, USA

(C) 2020 Copyright held by the owner/author(s).

ACM ISBN 978-1-4503-6793-6/20/03.

https://doi.org/10.1145/3328778.3366930

\section{INTRODUCTION}

Our group has organized over the past decade, approximately 600 hours of diversity training for computer science educators, varying from one-hour stand-alone classes to five-day diversity workshops. The participants worked in institutions spanning the educational gamut, from elementary school through college. Many of the workshops have included various forms of follow-up to measure impact, some of which have been reported elsewhere [5-7]. The discussion here is not about these workshops per se, but rather an experiential report of what we have learned about changing the mindset and behavior of workshop participants.

We acknowledge that much of this report is not research-validated principles but informed opinions based on extensive experiences obtained over many years. We believe that recording our experiences and lessons learned may both improve the quality of diversity training generally and provide seeds for future research validation.

Our claims in this paper are based on repeated experience and informed by several forms of feedback. In chronological order, we first read the room, seeing how engaged and accepting the participants appear as training is provided. We then notice the maturity and implication of participant questions: questions demonstrating interest and acceptance indicate successful training, while questions demonstratinf confusion and resistance to the material indicate a lack thereof. During workshops we also interact informally with participants and they often told us how they view other presenters' presentations. Most of our workshops include sessions where participants share their plans based on the training; we use the maturity of these plans and the number of concepts they embrace as further evidence of success. Finally, we conduct surveys of participants asking for feedback on each session, rating session quality and asking for comments. While not collected with the organization and controls needed for statistical validity, these multiple avenues of feedback have given us confidence in what we report herein.

Throughout this paper we refer to people providing diversity training as "presenters;" educators being trained as "participants;" and people the participants educate as "students," regardless of the actual job titles or multiple-role characteristics of the people involved.

\section{RELATED WORK}

A majority of the experiences reported here were achieved through the Tapestry and Lighthouse CC workshop series, about which several other papers have been written. Those previous papers describe workshop organization [7] and explore the impact of the workshops and specific workshop components [5, 6]. By contrast, this paper explores many aspects of presentation execution and organization which our team has not attempted to validated via 
controlled research but which we believe have sufficient consistency to be worth sharing.

The field of computing diversity has blossomed in the past thirty years. There is now an entire conference devoted solely to diversity in electrical engineering and computing [1]. Many papers addressing diversity have also appeared in other venues. That body of work has too many papers to cite individually. This paper is focused not on these research findings themselves but rather on how to disseminate findings effectively, particularly to those not already versed in the diversity literature.

Several previous papers have discussed delivering training to CS educators from diverse populations, but without mentioning any inclusion of direct diversity content $[2,4,9]$. By contrast, this paper reviews trainings delivered about diversity, regardless of the demographic characteristics of the participants themselves.

Other papers have described diversity interventions, either by itself or integrated with other trainings, including online courses $[5,18]$, in-person training $[7,20]$, and multi-modal interventions $[8,16,24]$. Each of them discusses some mix of intervention content and evidence of effectiveness. However, none compare their content and delivery to alternatives, nor discuss what particular aspects of presentation proved effective. This paper presents experiences both positive and negative, and includes direct advice for delivering successful training.

Gretter et al performed a survey of computing teachers in secondary schools and also a literature review. They concluded that teachers need various kinds of training and support, including being informed of best practices, awareness of broader issues of inequity, and exposure to models of equitable learning environments [13]. We focus on content delivery strategies more than particular content needs.

There are numerous professional diversity training approaches based on role-play or dramatization of case studies. We are unaware of any studies that evaluate their effectiveness for educators.

Previous publications have described various logistical considerations for running successful training workshops, including a workshop-in-a-box inspired by one of our workshop series [10]. We include no additional logistical recommendations in this paper.

We refer to core ideas of Cognitive Load Theory (CLT) throughout this paper [21]. While a full understanding of that learning theory is not needed to understand this paper, the reader should understand that (1) a schemata is a learned subconscious pattern of thought, good or bad, including stereotypes; (2) working memory is used for conscious thought and is limited in size; and (3) during cognitive overload, schemata can bypass already-full working memory and control actions without conscious intent.

\section{AVOIDING COMMON MISTAKES}

This section contains several mistakes we have made and/or observed others make, together with out understanding of why they were mistakes and, where applicable, tips on how to avoid them. We routinely try to correct failing practices as soon as we observe that they are failing, rather than designing experiments to verify that they do not work. Hence, experience reports like this are likely to be the only way of disseminating these failed practices.

\subsection{The privileged still worked}

A common thread in diversity literature and reporting is the idea of majority privilege, a concept introduced by Peggy McIntosh in 1989 [15]. Research supporting the existence of privilege has also recently shown that the privileged often doubt the impact of their privilege [17]. In our experience, even when people acknowledge a highly advantageous background and situation, they still consider themselves to have earned their position. Their memory of work and effort makes it difficult for them to feel their privilege as such.

We notice that when a presenter explains that the participants are privileged, those participants show signs of cognitive dissonance. As presenters, we observed this dissonance as us losing our audience. When observing others presenting this material and then discussing the presentations with the participants afterwards, participants often describes presenters as "out of touch" or used phrases suggesting they responded to their cognitive dissonance by dismissing all of what the presenters had said.

Our experience suggests that most of these problems can be resolved with just a single word change: instead of "privilege," refer to "resources." While this is not at true linguistic fit for the concept, we see less dissonance and more evidence of participants recognizing their advantages when we use a word that does not seem to them to downplaying their work.

We should note that this recommendation is based on short (less than an hour) presentations; with more time (and participants willing to remain engaged for more time) a detailed exploration of why privilege is the right word may be preferable.

\subsection{Typecasting is offensive to all}

A single offensive remark can lose an audience. The most common way we have observed (and to sometimes given) offense is to accidentally type-cast "the majority" as if they were all the same.

In the early years of giving training we would sometimes assert things about groups (e.g. "white males get more mentorship than other groups") and have some participants express offense because that was not true of them (e.g. "are you kidding? I got no mentoring and my female colleagues got a lot!"). We have since learned to use qualifiers like "often" and "typically" to avoid giving this kind of offense.

We have also experienced using the wrong pronoun when referring to a participant and otherwise suggesting some participants had membership in a group to which they did not identify, accidentally offending not just that individual but also other participants who recognized the mistake. While our intent was to appear personal and relate to the audience, we have learned not to assume any characteristic of a participant that they have not volunteered about themselves.

\subsection{Only preach to the choir}

The English idiom "preaching to the choir" refers to telling people things they already believe, with the implication that it is a waste of time to do so. However, when it comes to diversity training, "the choir"-i.e., those who already desire to improve diversity-are, in our experience, energized by preaching, while others are not.

We sometimes have participants in trainings (our own and others') confide in us that trainings were "politically correct nonsense", 
and convey a feeling of oppression of not being allowed to dissent. The way these confidences are shared suggest they see us, as people who visually present as belonging to the majority in computing, as likely allies who will sympathize with this attitude. They often indicate that they'll change observable behavior out of fear of repercussions if they do not, but reassert their belief that all of the pro-diversity content, whether it appealed to a sense of social justice or to objective results such as the fiscal superiority of diverse teams [3], failed to change their personal opinions.

We have seen some evidence of changed in such participants' opinions when presenters use indirection. Presenters who first share diversity-relevant topics in a context to which participants do not object (e.g., the stereotype threat of age and memory) and then observe how the same forces apply in other settings (e.g., the stereotype threat of race and academic ability) have been, in our experience, the most successful at changing opinions.

\subsection{Training is its own skill}

We have observed that two classes of presenters sometimes fail to connect with their audiences, despite having the knowledge and background to do so, if they are not given guidance on how to interact with the participants.

First is the disciplinary expert in a particular diversity topic. There are many reasons why an active contributor to the research in a topic is a good pick to present on that topic, but often such experts fail in two ways. Firstly, they tend to go too deep, presenting a detailed and nuanced view of their field that has too many pieces for novice participants to internalize, resulting in participants missing the big picture. Secondly, they tend to illustrate their topics with examples from their own discipline (often humanities and social sciences) that can leave participants from computing disciplines with a sense that it does not actually apply to them. That said, when experts provide a simplified high-level overview with concrete examples taken from technical disciplines, we find they connect well and are rated highly by us and by participants. We have had reasonable success steering presenters in this direction with a simple request that they do so.

Second is the highly successful member of a group underrepresented in computing. Presentations organized around challenges and the strategies they used to overcome them can be powerfully motivating and typically go quite well. But some presenters end up sharing atypical aspects of their personality and experiences that helped them succeed despite diversity-suppressing forces, resulting in their appearing different and unattainable. Particularly problematic are presenters who, when dealing with the common pressures of others saying "you cannot do this," react with "Oh yeah? Watch me!" We have not had much success in getting such presenters to focus on the more-relatable aspects of their experience instead.

\subsection{Changing schemata takes time}

One of the useful functions of the subconscious machinery in the brain is its ability to recognize and generalize patterns, providing our conscious minds with distilled information like "that looks like a hole in the road more than a shadow." Unfortunately, this machinery is an automated pattern recognizer [21], so it also provides subconscious pattern recognition such as "that person does not look like a computer scientist" when looking at someone of a lesscommon demographic group in the field. Because this processing is subconscious, it tends to impact the busy (who have less time to second-guess their subconscious) and the uninformed (who have both less understanding of why they should second-guess and have fewer contradicting schemata to help them) more than others [12]. This subconscious bias toward patterns can lead to several mistakes in presentations:

3.5.1 Less is more. In part because of the wealth of progress in understanding diversity-impeding phenomena over the past few decades, most presenters we have witnessed (ourselves included) try to fit more material into each presentation than the participants can usefully absorb. One noted presenter refused to end their session because they claimed their material was paramount. We have found an inverse correlation between the amount of material covered and the depth of understanding demonstrated by participants at the end of the training.

3.5.2 Summarize and revisit. Educational theory tell us that it takes multiple exposures to material for participants to learn it (see, e.g., $[11,22])$. Going back to summarize what has been shared in a session provides a second exposure. It is also valuable to refer back to earlier parts of the training in later parts with a brief refresher summary each time. While the presenters may feel like they are repeating themselves, we have observed that the participants usually welcome such summarizing and revisiting.

3.5.3 Beware of subconscious editorializing. Some specific patterns participants tend to have in their subconscious are easily triggered by presenters, resulting in the participants' schemata providing a counter-argument to the presenter. In particular. we have learned to watch out for for three particular patterns:

- Inability and anxiety are correlated. Stating underrepresented groups have extra stress and display less confidence can create a subconscious "which means they're probably unable" editorial.

- The inferior need more help than the superior. Suggesting that underrepresented groups benefit from extra support can create a subconscious "which means they're probably inferior" editorial.

- The majority are usually correct. Suggesting that false beliefs are commonly held can create a subconscious "which means they're probably true" editorial.

Because the conscious mind can overrule subconscious schemata, moving slowly to avoid cognitive overload around schemata-rich topics is especially important.

\subsection{Do not fight the world}

We observe that many presenters speak about diversity in a way that conveys a sense of fatalism or reinforces the message "everyone else believes $X$." If participants walk away with a reinforced belief that everyone knows group $X$ has characteristic $Y$, and a new belief that said "everyone" is wrong, then we find that in subsequent conversations those participants characterize the presentations as something like "some outlier came and told us why everyone is wrong." We assume this is due to the strength of their pre-existing "the majority is usually right" schemata.

One common practice that triggers a presenter-vs.-world mentality is to initially teach new principles in the context of diversity 
(see section 4.2 for a suggested pattern to avoid this). It also arises in presentations about mind-of-the-student phenomena such as stereotype threat and affinity support groups.

We have found that we can help participants correctly focus on student awareness rather than majority consensus, if presenters explain negative phenomena as depending on the existence of a stereotype, participant belief that a stereotype exists, or participant belief they are in the minority, rather than on being a minority.

We also see positive results when presentations use concrete examples of a stereotypes. We have found that the best such stereotypes are invented specifically for the presentation, with the three criteria of being plausible, easily stated, and unrelated to the audience.

\section{RECOMMENDED PRACTICES}

This section considers several principles of successful sessions and workshops. They are based on the hundreds of hours of leading and observing diversity-focused workshops. To our knowledge none have been formally studied. We hope that each of these will be either demonstrated or refuted by careful controlled studies. Given the time needed to measure each one individually, we share our experiences now.

\subsection{Build on a framework}

In our experience, participants generally do not share a robust mental models of cognition and learning presenters can use to help participants contextualize new information about how the experiences of diverse students might impact their learning. Thus, it is almost always worth the time to start with a brief summary of the relevant parts of some model; we have found cognitive load theory [21] to be readily understood and accepted by CS-trained participants and adequate to contextualize most diversity topics. In particular, we propose the following summary of cognitive load theory as short enough to explain briefly and sufficient to motivate many aspects of training.

- Your brain does much subconscious work using schemata. A schema is like an event handler producing higher-level ideas from lower-level sensation or schemata output. They are learned (i.e., not inborn), effectively permanent (i.e., in practice cannot be unlearned), and principally automate patterns we observe and actions we repeat.

- You use your working memory to do your thinking and learning, like the registers of a processor. Like registers, working memory is limited in how much it can store. We can think about large ideas because our schemata preprocess them into a small number of higher-level ideas.

- Anxiety reduces the available working memory, conceptually occupying some of that space in fretting about something, or biologically in hormone releases that draw blood away from the brain.

With these three concepts, it is then possible to pose many different ideas within this framework, including

- Stereotype threat [19]: awareness of a negative stereotype about you results in anxiety, either because you believe the stereotype and fret about being unfairly disadvantaged or because you do not, but feel you are representing your entire group and that if you fail you might confirm the stereotype in the minds of others.

- Implicit bias [12]: your brain has schemata equating "expected" with "good", and when your working memory is full those schemata subconsciously influence your actions.

- Pigeonholing: picking a role (or someone for a role) requires balancing more characteristics than fit in working memory, meaning schemata (including learned cultural expectation) have a significant impact.

- Affinity support groups: feeling alone can create anxiety; support groups for particular affinity groups can reduce that.

- Wise feedback [23]: struggling is interpreted by the "people like me aren't in computing" schema as evidence of inability; "I expect a lot" can provide an alternative explanation. Similarly, "I have confidence in you" can pit the "teacher is right" schema against the "people like me don't do this" schema.

In our experience, providing such a framework and tying each new idea back to it results in a higher level of comprehension.

A caveat here: not all of the topics presenters share were originally described under the same learning model. We've found trying to teach many models is distracting, but re-posing a finding in a new model is adding your own interpretation. It can be useful to first describe the phenomenon as observed in research; then remind participants that experiments readily show what happens but rarely why. The common framework used throughout the training can then be added as one possible explanation, not as known truth.

\subsection{Transition to diversity}

The goal of diversity training is to increase diversity. However, directly discussing diversity can raise heightened emotions (positive or negative) that can impede the rapid uptake of new material. Thus, we recommend presenting as much of the material as possible in a neutral context before transitioning to how it impacts diversity.

Following is a recommended template along with an example of how it might work in practice.

4.2.1 Provide a model. Explain a model of human thought, behavior, or reaction. The more closely you can match it to the kinds of models participants are used to thinking about professionally, the better this goes over.

Example: "Working memory is somewhat like the registers in a computer: it's fast and you have to use it to think, but there's not a lot of it. When you have too much to think about you experience cognitive overload, which is a bit like register spilling: you can function, but it takes more effort and time, possibly so much more that you fail to keep up with the real-time deadlines life imposes."

4.2.2 Add a neutral example. Show how the model helps explain something participants already accept and have no barriers up against talking about.

Example: "Have you ever had the experience of meeting someone new, asking their name, and realizing just a minute later that you cannot recall their answer? In the bustle of trying to think about who they are, what to say, how to act, and ..., your realtime scheduler decided to kill the 'remember their name' job to keep the higher-priority ones meeting their deadlines. Instead of spilling that register to the stack, you simply over-wrote it with 
something else. And since deciding which job had priority would have required registers itself, your subconscious almost certainly did this without consulting the part of your mind you think of as 'you'."

4.2.3 Transition to diversity. Add how the model also helps explain a disadvantage experienced by an underrepresented group.

Example: "Now imagine being in the same conversation, but the person you are meeting opens the conversation with 'wow, you look just like my ex.' Your subconscious is likely to pick worrying about 'are they thinking of me like their ex?' as higher priority than the things you would rather it prioritize. That worry consume registers of working memory, making remembering their name or even just keeping up with the conversation much less likely. This is not a choice: it is simply how brains work. If you talk long enough your brain may decide that the worry is unfounded, restoring your full working memory again, but until then you will just seem a bit more stupid than you are. And hope your brain does not pick up on your not being your best, lest it grab more registers worrying about that too!

"This extraneous overload is something experienced far more often when you are a member of a dramatically underrepresented and sometimes stigmatized group. Some of that working memory is occupied thinking 'are they focusing on my gender/skin tone/accent/height/disability/...?' and maybe, if you are part of not just an unusual but also a sometimes-suppressed group, 'are they thinking of me as inferior?' This can go away once you get to know them and your brain decides to stop worrying, but brains take time to break out of long-established habits and until then..."

\subsection{Avoid and prohibit myth-busting}

One aspect of diversity literature that often surprises many participants is the absence of diversity-impeding phenomena that depends on members of diverse populations believing that their population is less-able or inferior. Believing that other people believe in minority inferiority is important for stereotype threat [19]; believing that a group you do not belong to is inferior is one definition of explicit bias (see, e.g., [14]); observing some groups more than others leads to implicit bias [12]; but believing your own group is inferior rarely shows up in the literature.

We recommend explicitly telling participants to avoid mythbusting-that is, not to bring up a stereotype for the purpose of refuting it. After trying many ways to explain this principle, we believe the most effective to be the following:

Imagine that right before a competitive swim meet we tell you "I know you have heard that people with small feet do not swim well, but it's not true. We have done hundreds of studies and people with small feet swim just as well as those with big feet." This statement has communicates that 1 ) we noticed your small feet; 2) many people believe that small feet are detrimental; and 3) that it was worth our while to perform hundreds of studies to refute that detriment. In other words, we have created a perfect environment for stereotype threat where no threat existed in advance.
Presenting the ill-effects of myth busting almost always leads to questions from participants about how they are to combat stereotypes when they are raised by students. We have not been able to find research-backed suggestions for this scenario, perhaps because it is difficult to create the scenario where students naturally raise stereotypes on their own in a controlled research setting. Our best advice (backed only by anecdotal experiences) is to respond with surprise that the students would bring the stereotype up. Surprise can be an honest response even if this happens often, given that we hope our students know better than to believe stereotypes. An expression of surprise that students bring stereotypes up can help combat both the students' belief in the stereotype and their belief that the stereotype is widely believed.

\subsection{Welcome and expand on objections}

While in our experience it is uncommon for participants to raise objections to what is being presented, it does happen. Such objections can be powerful teaching tools provided the presenter treats them as such; we have found the following four-step response to be particularly effective at turning a participant's objection into a reinforcement of teaching:

(1) Listen closely and actively, ensuring you have properly understood their objection without suggesting any kind of judgment or response. This politeness helps the objector feel valued and helps prevent the mistake of responding to the objection you expected to hear instead of the one raised.

(2) Strengthen the objection to show you fully understand and are not worried by it. Do this with a hypothetical "what if a study showed $X$ ?" where $X$ would reinforce their objection. Strengthening the objection can help a response to the objection not be seen as a personal attack on the objector.

(3) Explain why the objection is invalid, but without suggesting it is foolish to have it. A useful template is "if we do not control for $Y$, it can look like that, but when we do...".

(4) Focus on the truth, not the falsehood, without overstating the evidence. "It's hard to know the absolute truth, but the majority of studies I've seen indicate...".

\subsection{Acknowledge cost}

The goal of diversity training is for the participants to alter their behavior, and altering behavior is challenging. In our experience, training is accepted with far more energy and care if presenters clearly acknowledge this difficulty and explicitly acknowledge that change requires energy and investment.

We particularly recommend acknowledging three kinds of cost:

Investing Time Anything you add comes at the cost of something removed. If you spend an extra ten minutes re-writing an assignment to not use stereotype-triggering language, those ten minutes were not spent improving some other aspect of the course.

Changing is Hard Changing minds (including your own), is hard. It takes time and energy to create an environment where everyone thrives, and often takes multiple passes to get it right. We regularly hear experts in diversity with decades of experience say something with an unfortunate connotation, hear 
what they just said, and correct themselves. Expect true change to take time.

Perpetual Cost Communication is easier when you are communicating with those like yourself. The more successful you are at increasing diversity, the less shared culture and experience you will be able to use in communication and thus the harder communication will become. Increased diversity has its own benefits, which we believe outweigh the costs, but there is a qualitative change in the feel of a classroom (or workplace) as it becomes more diverse.

We find that a discussion of costs at the end of a training workshop generally results in participants, many of whom are habitual problem-solvers, immediately beginning to discuss how these costs can be worked around in their situations. Although we have no direct evidence in its support, we hope that it will also help them to see any future lack of progress is as at least in part lack of sustained investment and will then increase their persistence in diversityimproving efforts.

\subsection{Appeal to many motivations}

Presenters often express their motivation for providing diversity training as a combination of a sense of social equity, a desire to end injustice, and hope for a demographically-representative workforce. Participants more often express their motivation as some combination of helping those struggling succeed and helping the brightest excel, with the balance between those varying by the individual. There are many exceptions to these broad trends among both presenters and participants, and other objectives too: some want to minimize complaints, have happy students, feel good about themselves, get good reviews, please their boss, feel in control, etc.

In any case, we have observed that when presenters focus on just one or two motivations, they tend to lose participants who were differently motivated. We have found that training works best when many objectives are acknowledged, but none are made the focus. We find this difficult ourselves because we naturally tend to think about interventions as tools toward the objectives we care about most. However, we find that taking the time during preparation to ponder what other objectives they might support and to mention those in the presentation yields a much more engaged group of participants. Even participants who do not value diversity often value objectives that diversity-supporting practices also support.

\section{CAVEATS}

There are three caveats to which readers should keep in mind.

None of these practices have been studied in targeted, controlled research. While we have measured the effectiveness of the workshops in which these principles are applied [7], those measures have not been designed to measure the effectiveness of particular presenter behaviors. We hope all of the tips in this paper will eventually be studied and either validated or refuted. We recognize that several of these tips, notably those oriented around reacting to participant actions (e.g., sections 3.6 and 4.4), will be difficult to study in a controlled environment.

While we have also assisted in the preparation and execution of online training, most of this paper is based on our experience with in-person training with an informative, rather than experiential, design. We have not yet found an effective way of determining best practices in online training and do not have much experience with case-study or role-play based training.

Our experiences includes observing dozens of other presenters as well as team members. However, they are filtered through our personal perceptions. We hope other presenters will publish their own observations and tips so that a consensus of best practices may emerge.

\section{CONCLUSION AND FUTURE WORK}

In our experience, there are many aspects to effective diversity training beyond simply the content presented. We have shared here both practices we have found valuable to implement and ones we recommend avoiding. We think sharing both is important, and encourage others share both as well.

In addition to designing studies to validate the specific suggestions contained in this paper, we look forward to continuing to explore better practices for helping participants make meaningful change. We are especially concerned with how to better address the following:

- Given the many areas in which a participant could improve, how can presenters help them make an effective plan on what changes to make and when?

- How can presenters help participants understand the trade-offs of apparently contradictory best practices? For example,

- Affinity support groups can reduce a sense of isolation, but can also reinforce a sense of being different.

- Being open about personal interests helps students feel welcome, but sharing stereotypical interest can hurt their sense of belonging.

- Allowing assessment re-takes can reduce ambient anxiety and build a growth-mindset, but can also communicate that "group $X$ needs two tries."

- What practices result in long-term behavior change by participants?

We expect that by following the tips in this paper, the effectiveness of diversity training may be increased generally and that other presenters can be saved the many hours of iteration in producing effective training. We look forward to future research to explore the effectiveness of these and other suggestions in a controlled setting. We also hope that this paper will inspire others to share their suggestions and best practices so that we may learn from them and that as a community we may become better at helping all of our colleagues understand how to teach all students effectively.

\section{ACKNOWLEDGMENTS}

This document would not have been possible without one of the co-founders Tapestry and Lighthouse Workshop series, the now departed Joanne McGrath Cohoon. We are also indebted to funding and support from the NSF, NCWIT, the University of Virginia, and the many institutions who have hosted our trainings; we also owe much to the many workshop presenters we have worked with and observed, including the other presenters in the Lighthouse team: Leslie Cintron, Yeunjeong Chang, and Britney Halsey and the many subject-matter experts who have given of their time and knowledge as presenters in our workshops. 


\section{REFERENCES}

[1] 2018. Research on Equity and Sustained Participation in Engineering, Computing, and Technology (RESPECT). http://respect2018.stcbp.org/

[2] Linda Akli, Jay Alameda, Steven I. Gordon, Marcela Madrid, and Lorna Rivera. 2016. XSEDE Training: Achieving Access and Inclusion. In Proceedings of the XSEDE16 Conference on Diversity, Big Data, and Science at Scale (XSEDE16). ACM, New York, NY, USA, Article 55, 6 pages. https://doi.org/10.1145/2949550.2949586

[3] Lecia Barker, Cynthia Mancha, and Catherine Ashcroft. 2014. What is the Impact of Gender Diversity on Technology Business Performance: Research Summary https://www.ncwit.org/businesscase

[4] Bradley Beth, Calvin Lin, and George Veletsianos. 2015. Training a Diverse Computer Science Teacher Population. ACM Inroads 6, 4 (Nov. 2015), 94-97. https://doi.org/10.1145/2829978

[5] Yunjeong Chang, Leslie Cintron, James P. Cohoon, and Luther Tychonievich. 2018. Diversity-focused Online Professional Development for Community College Computing Faculty: Participant Motivations and Perceptions. In Proceedings of the 49th ACM Technical Symposium on Computer Science Education (SIGCSE '18). ACM, New York, NY, USA, 783-788. https://doi.org/10.1145/3159450.3159505

[6] Leslie Cintron, Luther Tychonievich, James Cohoon, YunJeong Chang, Brittany Halsey, Devon Yi, and Genevieve Schmitt. 2019. Exploring Underrepresented Student Motivation and Perceptions of Collaborative Learning-Enhanced CS Undergraduate Introductory Courses. In 2019 IEEE Frontiers in Education Conference (FIE). to appear.

[7] James P. Cohoon, J. McGrath Cohoon, Luther A. Tychonievich, and Catherine E. Brawner. 2013. Tapestry Workshops: Helping High School Teachers Grow and Diversify Computing. In 2013 ASEE Annual Conference \& Exposition. ASEE Conferences, Atlanta, Georgia. https://peer.asee.org/22517

[8] Teresa Dahlberg, Tiffany Barnes, Kim Buch, and Audrey Rorrer. 2011. The STARS Alliance: Viable Strategies for Broadening Participation in Computing. Trans. Comput. Educ. 11, 3, Article 18 (Oct. 2011), 25 pages. https://doi.org/10.1145/ 2037276.2037282

[9] Peggy Doerschuk, Jiangjiang Liu, and Judith Mann. 2011. INSPIRED High School Computing Academies. Trans. Comput. Educ. 11, 2, Article 7 (July 2011), 18 pages. https://doi.org/10.1145/1993069.1993071

[10] National Center for Women \& Information Technology (NCWIT). 2017. Tapestry Workshop-in-a-Box: Professional Development for High School Teachers. https: //www.ncwit.org/tapestry

[11] Howard Gardner. 1999. The disciplined mind: What all students should understand. Simon \& Schuster, New York.

[12] Anthony G. Greenwald and Mahzarin R. Banaji. 1995. Implicit Social Cognition: Attitudes, Self-Esteem, and Stereotypes. Psychological Review 102, 1 (1995), 4-27.
[13] Sarah Gretter, Aman Yadav, Phil Sands, and Susanne Hambrusch. 2019. Equitable Learning Environments in K-12 Computing: Teachers' Views on Barriers to Diversity. ACM Trans. Comput. Educ. 19, 3, Article 24 (Jan. 2019), 16 pages. https://doi.org/10.1145/3282939

[14] Ivy W. Maina, Tanisha D. Belton, Sara Ginzberg, Ajit Singh, and Tiffani J. Johnson. 2018. A decade of studying implicit racial/ethnic bias in healthcare providers using the implicit association test. Social Science \& Medicine 199 (2018), 219-229. https://doi.org/10.1016/j.socscimed.2017.05.009

[15] Peggy McIntosh. 1989. White Privilege: Unpacking The Invisible Knapsack. Peace and Freedom Magazine (July/August 1989), 10-12.

[16] J. Payton, T. Barnes, K. Buch, A. Rorrer, and H. Zuo. 2015. STARS computing corps: Enhancing engagement of women and underrepresented students in computing. In 2015 Research in Equity and Sustained Participation in Engineering, Computing, and Technology (RESPECT). 1-6. https://doi.org/10.1109/RESPECT.2015.7296495

[17] L. Taylor Phillips and Brian S. Lowery. 2015. The hard-knock life? Whites claim hardships in response to racial inequity. Journal of Experimental Social Psychology 61 (2015), 12-18. https://doi.org/10.1016/j.jesp.2015.06.008

[18] Guido Rößling and Felix Broj. 2018. An Interactive Online Course to Raise Awareness About Diversity. In Proceedings of the 23rd Annual ACM Conference on Innovation and Technology in Computer Science Education (ITiCSE 2018). ACM, New York, NY, USA, 377-377. https://doi.org/10.1145/3197091.3205809

[19] Claude Steele and Joshua Aaronson. 1995. Stereotype threat and the intellectual test performance of African Americans. Fournal of Personality and Social Psychology 69, 5 (1995), 7987-811. https://doi.org/10.1037/0022-3514.69.5.797

[20] P. Sweany. 2015. Designing a pre-service CS teacher education program with a focus on diversity. In 2015 Research in Equity and Sustained Participation in Engineering, Computing, and Technology (RESPECT). 1-2. https://doi.org/10.1109/ RESPECT.2015.7296514

[21] John Sweller. 1988. Cognitive Load During Problem Solving: Effects on Learning. Cognitive Science 12, 2 (1988), 257-285. https://doi.org/10.1207/ s15516709 $\operatorname{cog} 1202 \_4$

[22] Judy Willis. 2007. Review of Research: Brain-Based Teaching Strategies for Improving Students' Memory, Learning, and Test-Taking Success. Childhood Education 83, 5 (2007), 310-315, https://doi.org/10.1080/00094056.2007.10522940

[23] David Scott Yeager, Valerie Purdie-Vaughns, Julio Garcia, Nancy Apfel, Patti. Brzustoski, Allison Master, Wwilliam T. Hessert, Mathew E. Williams, and Geoffrey L. Cohen. 2014. Journal of Experimental Psychology: General (August 2014). https://doi.org/10.1037/a0033906

[24] N. Zhou, D. Richardson, and M. Warschauer. 2018. Promoting High School Teachers' Self-efficacy and the Understanding of Equity Issues in CS Classrooms. In 2018 Research on Equity and Sustained Participation in Engineering, Computing, and Technology (RESPECT). 1-8. https://doi.org/10.1109/RESPECT.2018.8491713 